\title{
Keep our guard up against general anesthesia for cesarean section!
}

\author{
Hiroyuki Sumikura
}

Received: 4 April 2012/ Accepted: 19 April 2012/Published online: 19 May 2012

(C) Japanese Society of Anesthesiologists 2012

Keywords Difficult airway - Cesarean section · General anesthesia

Obstetric airway has been recognized as a challenge to anesthesiologists [1-3]. In this issue, Tao et al. reported that unanticipated difficult airway accounted for $0.56 \%$ of all pregnancy-related surgical patients, and that more than $99.9 \%$ of all obstetric patients could be intubated [4]. I believe this report is valuable because it shows an actual ratio of unanticipated difficult airway in parturients in their hospital. However, I write this editorial to express some concerns, because some readers may misread this article to be optimistic. First, it should be noted that Tao et al. report a ratio of unanticipated difficult airway. Hence, there must exist some cases with anticipated difficult airway. It is a great pity, however, that they showed neither number nor ratio of anticipated difficult airways in spite of their careful preoperative or prenatal airway evaluation.

The most frequently cited article to discuss the risk of general anesthesia for cesarean section is the one by Hawkins et al. [5] reporting that, during the 1970s and 1980s, 17 women died as a result of general anesthesia for every 1 woman who died of regional anesthesia-related causes. This article has played an important role in building the consensus that general anesthesia should be avoided for cesarean section. Simultaneously, monitors for respiratory

This comment refers to the article available at doi:10.1007/s00540-012-1338-1.

\section{H. Sumikura $(\square)$}

Department of Obstetric Anesthesia,

National Center for Child Health and Development,

2-10-1 Okura, Setagayaku, Tokyo 157-8535, Japan

e-mail: sumikura-h@ncchd.go.jp status and devices for airway management were developed, contributing to the improved safety of general anesthesia for cesarean section. As a result, the gross number of maternal deaths decreased dramatically. Furthermore, the resulting risk ratio between the two techniques also decreased, to 1.7 [6]. However, some maternal deaths still occur related to anesthesia, and anesthesiologists possibly involved in obstetrics should not be optimistic [7, 8].

Until today, several strategies have been proposed and practiced to avoid general anesthesia for cesarean section. Placement of an epidural catheter for labor analgesia can contribute to the reduction of general anesthesia by offering an epidural anesthesia for urgent cesarean section during delivery. Prenatal anesthetic evaluation and explanation, including a parturient who is not willing to receive an epidural, can also contribute in avoiding, by screening, high-risk parturients for general anesthesia and by encouraging an epidural for their delivery or planned cesarean section. With these efforts, it is reported that the ratio of general anesthesia to cesarean section can be decreased to less than $1 \%$ [9]. Recently, a new strategy to avoid general anesthesia for cesarean section has been proposed by Kinsella et al. [10]. They state that most urgent cesarean sections can be managed by spinal anesthesia, naming this strategy rapid sequence spinal anesthesia (RSS), imitating rapid sequence induction (RSI) for general anesthesia. I believe that Tao's hospital was also making every effort to avoid general anesthesia for cesarean section; however, it should be noted that the general anesthesia ratio is relatively high in their hospital. And again, it is a pity that they could not show the number of parturients with anticipated difficult airways, and they could not explain how they treated them.

On the other hand, it is also important to improve the safety of general anesthesia for cesarean sections as it 
cannot be reduced to $0 \%$. For this purpose, establishment of an algorithm for a difficult airway, preparation of a difficult airway cart, and simulation training have been proposed. Especially, the need for simulation training has been a focus because of the decreased chance of training for general anesthesia for cesarean section in practical settings. From this point of view, residents of Tao's hospital seem to be lucky as they can experience a number of cases of general anesthesia for cesarean section. However, as their report ironically demonstrated that a difficult airway was more likely to be encountered by anesthesia providers with less than 1 year of experience, it should be discussed if they can allow their residents to intubate the trachea for cesarean section.

Another concern is a trend to ease restriction on preoperative fasting (NPO, nothing per os). As the number of maternal death has decreased, it has been proposed that NPO policy during delivery and before surgery should not be as strict as we have practiced [11]. However, it should be noted that some maternal deaths still occur as a result of failed intubation and aspiration pneumonia. As the recent increase in the number of obese parturients causes further risk of failed intubation and aspiration pneumonia, the NPO policy should not be relaxed for these parturients.

Considering these trends together, I would like to strike a warning that it is too early to let our guard down against general anesthesia for cesarean section. I suggest readers interpret this report by Tao et al. to indicate that unanticipated difficult airway occurred in 1 in 200 patients in spite of careful evaluation, and among 12 parturients with unanticipated difficult airway, 2 parturients were not intubated and aspiration pneumonia was suspected in 1 parturient. We should keep on with every effort to avoid general anesthesia for cesarean section and to improve techniques to manage difficult airway of parturients.

\section{References}

1. Vasdev GM, Harrison BA, Keegan MT, Burkle CM. Management of the difficult and failed airway in obstetric anesthesia. J Anesth. 2008;22:38-48.

2. Mhyre JM, Healy D. The unanticipated difficult intubation in obstetrics. Anesth Analg. 2011;112:648-52.

3. Douglas MJ, Preston RL. The obstetric airway: things are seldom as they seem. Can J Anaesth. 2011;58:494-8.

4. Tao W, Edwards JT, Tu F, Xie Y, Sharma SK. Incidence of unanticipated difficult airway in obstetric patients in a teaching institution. J Anesth. 2012 (in press).

5. Hawkins JL, Koonin LM, Palmer SK, Gibbs CP. Anesthesiarelated deaths during obstetric delivery in the United States, 1979-1990. Anesthesiology. 1997;86:277-84.

6. Hawkins JL, Chang J, Palmer SK, Gibbs CP, Callaghan WM. Anesthesia-related maternal mortality in the United States: 1979-2002. Obstet Gynecol. 2011;117:69-74.

7. Mhyre JM, Riesner MN, Polley LS, Naughton NN. A series of anesthesia-related maternal deaths in Michigan, 1985-2003. Anesthesiology. 2007;106:1096-104.

8. Kinsella SM. Anaesthetic deaths in the CMACE (Centre for Maternal and Child Enquiries) Saving Mothers' Lives report 2006-08. Anaesthesia. 2011;66:243-6.

9. Palanisamy A, Mitani AA, Tsen LC. General anesthesia for cesarean delivery at a tertiary care hospital from 2000 to 2005: a retrospective analysis and 10-year update. Int J Obstet Anesth. 2011;20:10-6.

10. Kinsella SM, Girgirah K, Scrutton MJL. Rapid sequence spinal anaesthesia for category-1 urgency caesarean section: a case series. Anaesthesia. 2010;65:664-9.

11. ASA (2007) Practice guidelines for obstetric anesthesia: an updated report by the American Society of Anesthesiologists Task Force on Obstetric Anesthesia. Anesthesiology 106:843-63. 